\title{
DIAGNÓSTICO DE CARCINOMA MAMÁRIO EM CÃO MACHO: RELATO DE CASO
}

\author{
Karine Keller REZENDE* \& Ana Paula de Aragão GAMA
}

Centro de Ensino Superior de Valença. Valença, Rio de Janeiro, Brasil.

*Autor para correspondência: karinekeller.vet@ gmail.com

DOI: http://dx.doi.org/10.18571/acbm.180

\section{RESUMO}

O Brasil é o segundo maior país no mundo quando o assunto é população canina, possuindo cerca de 52 milhões de cães. Dentre as patologias diagnosticadas entre cães, os tumores ocupam um lugar de destaque. Um dos tipos de neoplasias mais frequentes, principalmente em cadelas, são os tumores mamários, que nelas são responsáveis por cerca de $52 \%$ do total das neoplasias, sendo 50\% destes malignos. Os tumores mamários em cães machos apresentam baixa incidência, mas alta malignidade. Este trabalho tem como objetivo relatar o caso de um cão macho sem raça definida de 14 anos, que foi atendido em uma clínica veterinária localizada na cidade de Queimados, RJ. O mesmo apresentava aumento de volume na região abdominal próximo ao prepúcio, onde foi realizada cirurgia para retirada do tumor e diagnóstico através do exame histopatológico. O diagnóstico foi de um tumor misto maligno de mama (carcinoma complexo), o animal foi encaminhado para tratamento oncológico.

Palavras-chave: Neoplasia mamária; Macho; Histopatologia.

\begin{abstract}
Diagnostic of breast carcinoma in male dog - Case Report. Brazilis the second largest country in the world when the subjectis canine population, possessing about 52 million dogs. Among the pathologies diagnosed among dogs, tumors occupy a prominent place. One of the most frequent types of cancers in dogs, especially bitches, is mammary tumors, which account for about $52 \%$ of all neoplasms, $50 \%$ of which are malignant. Mammary tumors in male dogs present low incidence but high malignancy. This work aims to report the case of a 14 year old male dog, Who was treated at a veterinary clinic located in the city of Queimados, Rio de Janeiro. It had na increase in volume in the abdominal region near the foreskin, where surgery was performed for removal of the tumor and diagnosis byhistopathological examination. The diagnosiswas of a mixed malignant breast tumor (complex carcinoma), the animal was referred for câncer treatment.
\end{abstract}

Keywords: Breast neoplasm; Male; Histopathology.

\section{Introdução}

Um dos tipos de neoplasias mais frequentes em cães, principalmente em cadelas, são os tumores mamários, que nelas são responsáveis por cerca de $52 \%$ do total das neoplasias (MENDES, 2007), onde, segundo Queiroga (2002) e Lopes (2002), pode-se observar que 50\% destes, são malignos. Sua ocorrência em machos quase não é descrita pela literatura. Entretanto, por conta da proximidade fisiológica dos tumores mamários entre seres humanos e cães, pode fazer uma comparação, uma vez que esse tipo de neoplasia em homens também é raro, com incidência inferior a 1\% se comparada a relatada em mulheres (KUMAR, 2013).

Os carcinomas são um dos tipos histológicos mais presentes em neoplasias mamárias de cadelas (RIBEIRO, 2010). Eles são classificados conforme sua penetração ou não na membrana 
basal limitante, aqueles que ficam dentro do limite são denominados de carcinomas in situ e os que se espalham para além dele são chamados de carcinoma invasivo ou infiltrativo (KUMAR; ABBAS; ASTER, 2013).

O acompanhamento de certas doenças é de fundamental importância para manutenção do bem-estar animal, sendo os tumores mamários um risco para sua saúde e qualidade de vida (FONSECA, 2000).

A identificação dos tumores que acometem os cães, auxilia na execução do tratamento mais indicado, sendo ele cirúrgico, oncológico ou experimental e a avaliação frequente permite constatar a eficácia dos mesmos, fornecendo um possível prognóstico (RIBEIRO, 2010).

Segundo Zachary e McGavin (2013), o desenvolvimento da neoplasia epitelial pode ser dado de diversas formas, uma delas é a progressão de uma hiperplasia ductal ou lobular para uma displasia e depois para uma neoplasia, e outra é através de uma forma não invasiva para uma invasiva. Os tumores podem surgir em apenas uma ou em várias glândulas mamárias, sendo essencial o diagnóstico e prognóstico de todas elas, pois vários tipos de neoplasias podem ser encontrados no mesmo paciente. Geralmente, estão ligados a idade dos animais e ao fato de não serem castrados, pois acredita-se que, em cadelas, são altamente influenciados pela ação hormonal. A probabilidade de ocorrência desta neoplasia aumenta em animais de meia idade e idosos, sem predisposição racial (QUEIROGA, 2002; LOPES, 2002). Segundo Fergunsson (1985), as cadelas que passam por ovariosalpingohisterectomia $(\mathrm{OSH})$ antes do primeiro estro apresentam risco de 0,5\% de desenvolverem tumores de mama, $8 \%$ de risco em OSH após o primeiro estro e 26\% após o segundo estro.

Estudos mais aprofundados sobre a ocorrência de tumores mamários, seus cursos e suas causas, são importantes para que se saiba o que está acarretando o desenvolvimento dessa forma neoplásica e qual o melhor caminho para se abordar certos tipos de tumores. Sendo assim, informações sobre o prognóstico e manutenção da qualidade de vida do paciente podem ser fornecidas, provendo o máximo de subsídios disponíveis sobre o manejo do animal (HELLMEN et al., 1993).

O objetivo deste projeto é relatar a ocorrência de tumor mamário em um cão sem raça definida (SRD) macho, atendido em uma clínica veterinária na cidade de Queimados no Estado do Rio de Janeiro.

\section{Relato de caso}

O animal utilizado no estudo foi um cão macho, SRD de 14 anos de idade que foi atendido em uma clínica veterinária localizada na cidade de Queimados, Estado do Rio de Janeiro.

Para a realização do estudo, foi utilizado tumor removido cirurgicamente para análises histopatológicas.

O animal chegou a clínica veterinária onde a principal queixa do tutor era a presença de um aumento de volume no abdômen ao lado do prepúcio. O mesmo foi atendido e após exame clínico completo suspeitou-se de hérnia abdominal. Após avaliação mais criteriosa, constatou-se de que se tratava de um tumor em região hipogástrica periprepucial. A descrição macroscópica era de uma massa lateral ao pênis de aspecto irregular parcialmente coberta por pele com pelos. Desta forma, foi indicado que o mesmo fosse internado para realização de procedimento cirúrgico, afim de se extrair totalmente o tumor.

Após o procedimento cirúrgico o animal recuperou-se satisfatoriamente e o material coletado foi encaminhado para avaliação histopatológica. As amostras foram coletadas em recipientes compatíveis com seu tamanho contendo formol a 10\% (Figura 1).

$\mathrm{Na}$ avaliação macroscópica histopatológica para início do diagnóstico, constatou-se que a massa era macia aos cortes e sua superfície de corte era, ora compacta brancacenta ora cística com conteúdo marrom gelatinoso (Figura 1B). 

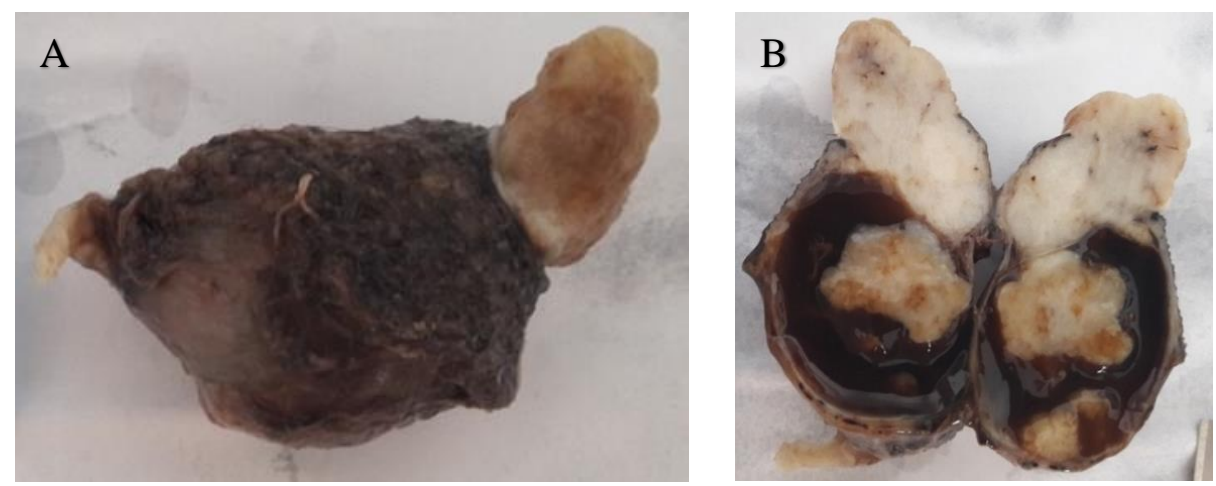

Figura 1: (A) Tumor de mama retirado cirurgicamente e conservado em formol a $10 \%$.

(B) Corte Medial do tumor mamário.

A massa foi fracionada e preparada para ser colocada em lâminas para realização análise microscópica. A avaliação microscópica revelou uma proliferação de células epiteliais com discreta anaplasia, distribuídas em pequenas formações túbulo papilares e com grandes formações císticas (Figura 2 A e B).
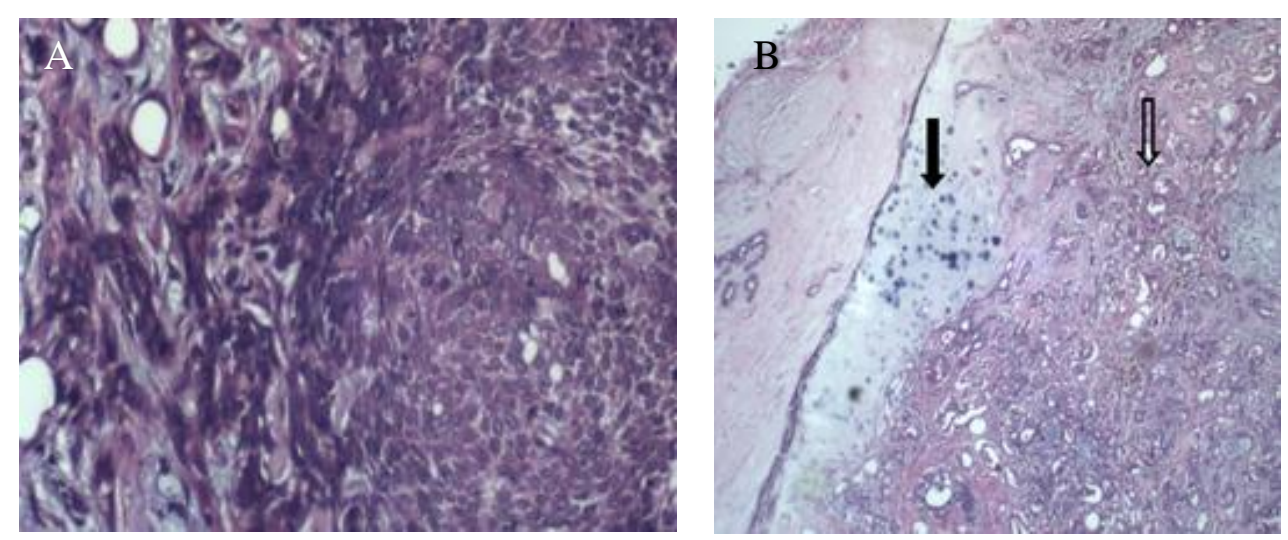

Figura 2: Microscopia do tumor removido. (A) Proliferação de células epiteliais com discreta anaplasia. (B) Proliferação de células epiteliais distribuídas em pequenas formações túbulo papilares (seta) e, no permeio, verificam-se áreas de diferenciação condroide (seta cheia). H.E. Obj. 4x. H.E. Obj.

No permeio, verificaram-se proliferação de células mioepiteliais que, em algumas áreas, exibiram diferenciação condroide (Figuras 3 A e B). Observaram-se ainda infiltrado inflamatório mononuclear (Figura 3A). As margens cirúrgicas avaliadas não foram mantidas. O diagnóstico foi de tumor misto maligno de mama (carcinoma complexo), extremamente raro em cães machos. Foi recomendado que o animal seguisse para avaliação com médico veterinário oncologista.
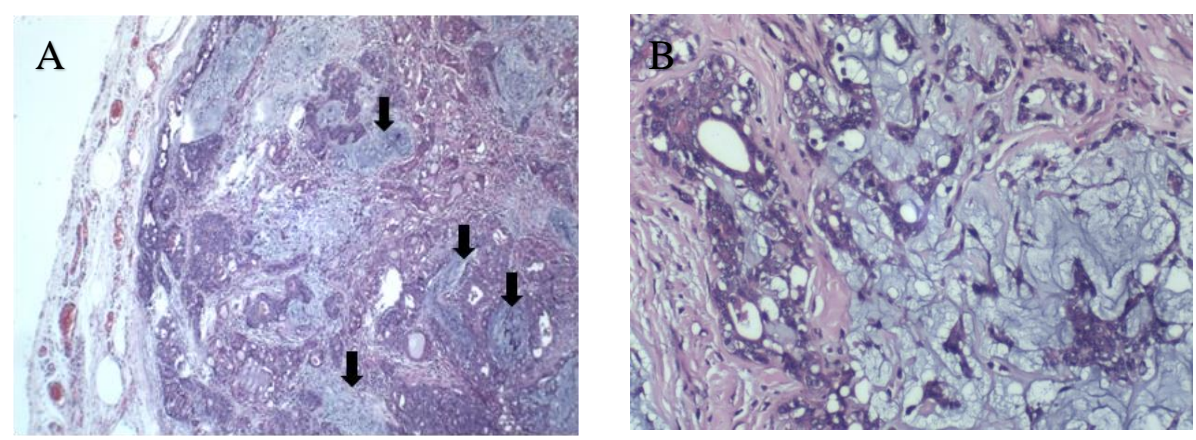

Figura 3: Proliferação de células mioepiteliais que, em algumas áreas, exibem diferenciação condroide. (A) H.E. Obj. 4x (seta cheia) e (B) H.E. Obj. 20x. 


\section{Discussão}

O cão, por se tratar de um animal idoso, vai de acordo com o que afirma Cassali (2017), que cita o aumento da expectativa de vida como uma das prováveis causas da maior ocorrência de tumores mamários em cães, assim como na população humana. Segundo Queiroga (2002), Lopes (2002) e Santos et al. (2009), essa longevidade é ainda mais séria quando o animal não foi submetido à gonadectomia, ou passou por este procedimento tardiamente, no caso das cadelas, após o segundo estro, aumentando as chances de desenvolvimento de tumores mamários, que são altamente relacionados a hormônios sexuais. Cães machos que desenvolvem tumores mamários tendem a apresentar esta alteração nas mamas abdominais caudais e inguinais (CASSALI, 2017).

\section{Conclusão}

O exame histopatológico é de suma importância na identificação de tumores, principalmente os mamários. As neoplasias mamárias em cães machos são raras e eventos como este, intensificam a necessidade para melhores diagnósticos clínicos e laboratoriais, visando uma melhor qualidade de vidas aos pacientes, principalmente os oncológicos.

\section{Referências}

CASSALI, G. D. Patologia Mamária Canina. 1. ed. São Paulo: Medvet, 2017.

FERGUNSSON, H. R. Canine mammary gland tumors. Veterinary Clinics of North America: Small Animal Practice, v. 15, n. 3, p. 501-511, 1985.

FONSECA, C. S.; DALECK, C. R. Neoplasias mamárias em cadelas: influência hormonal e efeitos da ovário-histerectomia como terapia adjuvante. Ciência Rural, v. 30, n. 4, p. 731-735, 2000 .

HELLMEN, E. et al. PrognosticFactors in Canine Mammary Tumors: A MultivariateStudy of 202 Consecutive Cases. VetPathol, v. 30, n. 1, 1993.

KUMAR, V.; ABBAS, A. K.; ASTER, J. C. Robins Patologia Básica. 9. ed. Rio de Janeiro: Elsevier, 2013. p. 710-714.

MENDES, T. C. et al. Comparação entre os sistemas histomorfológicos e de graduação histológica para classificação prognóstica de tumores mamários em cadelas. Acta Scientiae Veterinariae, v. 35, n. 3, p. 339-343, 2007.

QUEIROGA, F.; LOPES, C. Tumores mamários caninos - Novas perspectivas. Congresso de Ciências Veterinárias, Oeiras, v. 10, n. 12, p. 183-190, 2002.

RIBEIRO, G. M. Carcinoma em Tumor Misto de Mama da Cadela: Avaliação de Aspectos Morfológicos e Perfil Imunofenotípico. 2010. 115f. Tese (Mestrado) Universidade Federal de Minas Gerais, Belo Horizonte, Minas Gerais, 2010.

SANTOS, F. C. et al. Complicações da esterilização cirúrgica de fêmeas caninas e felinas Revisão de literatura. Veterinária e Zootecnia. v. 16, n. 1, p. 8-18, 2009.

ZACHARY, J. F.; McGAVIN, M. D. Bases da Patologia em Veterinária. 5. ed. Rio de Janeiro: Elsevier, 2013. p. 1089-1129. 